\title{
ARAB WOMEN ENTREPRENEURS IN SPAIN: LIKE CEDARS BESIDE THE STREAM
}

Marina Roig, Lourdes Susaeta, Esperanza Suárez, José Ramón Pin 



\title{
ARAB WOMEN ENTREPRENEURS IN SPAIN: LIKE CEDARS BESIDE THE STREAM
}

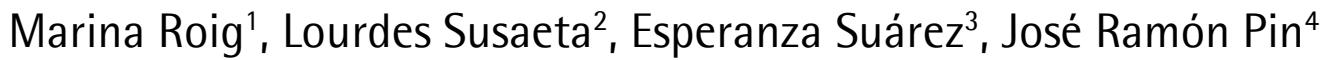

\begin{abstract}
This paper presents the results of a qualitative study* designed to give a "voice" to women entrepreneurs in Spain who come from different backgrounds but are united by their Arab roots and common culture. The purposes of the present study are twofold: (1) to add to the scarce research on women entrepreneurs regarding the role of macrosocietal values and traditions and (2) to understand better the dynamics of the Arab world as they relate to women entrepreneurs and Islam, specifically the implications of gender roles and work (Gray and Finley-Hervey, 2005). We study these questions in the Spanish context, where a renewed entrepreneurship culture is being revived, partly as a result of the economic crisis that started in 2008. In a related vein, the intersectionality of different influences that converge on the entrepreneurial impulse is a conglomerate of Islamic values and gender negotiations within the Spanish context. We seek to explore notably different aspects that characterized our sample - that is, the main factors that influence Arab women on their path to entrepreneurship; self-employment as a real means for women to engage in the labor market (Faveri et al., 2015) and as an invaluable tool for agency and empowerment (EBRD, 2015); entrepreneurship as a way to procure the involvement of Arab women in the public space; and finally, formal and informal features that contextualize the entrepreneurial activity of this particular immigrant group in Spain. Case study research via semistructured interviews has been the methodology used for this investigation. Thus, we conducted some interviews that shed light on important information and we have found through our analysis that the main formal and informal factors in this matter are educational level, personal ambition, the implications of family commitments, economic necessity and social and cultural patterns. The last three factors are the ones that are intrinsically linked to the Arab women studied in our research. All these issues are addressed in depth in our paper, with which we expect to contribute to the debate on gender roles and women's economic dimension by means of entrepreneurship.
\end{abstract}

Keywords: Entrepreneurship; Arab women; Empowerment; Stereotypes; Patriarchy; Family commitments

\footnotetext{
* This study has been possible thanks to the help and support given by a Citi Foundation grant, ID number 20152024, as part of the Entrepreneurship and Internationalization of Startups Program. We would also like to express our gratitude to Olivia Orozco and all the participants for having shared their opinions and experiences.

${ }^{1}$ Research Assistant, IESE.

${ }^{2}$ Professor at the ISEM, University of Navarra.

${ }^{3}$ Associate Researcher.

${ }^{4}$ Professor of Managing People in Organizations and Business Ethics José Felipe Bertrán Chair of Governance and Leadership in Public Administration IRCO - International Research Center on Organizations, IESE
} 


\section{ARAB WOMEN ENTREPENEURS IN SPAIN: LIKE CEDARS BESIDE THE STREAM}

\section{Introduction}

We are immersed in the second wave of globalization, within a continuously changing scenario characterized by constant flows of people, data and goods. This second wave of globalization is a fact with which society, ethics and politics have to interact. Different motivations fuel the migration phenomenon that characterizes this wave, with people usually migrating to escape poverty and procure financial security for their families. Gender questions are also an important part of these new scenarios, even more so if they go hand in hand with international migration to a new society and culture. Women act as "bridges between (both) cultures" (Cebrián, 2008), and their critical role in the host society derives from this. Women are traditionally given the task of safeguarding their own culture while having to enable their families to adjust to the new scenario. Furthermore, this paper focuses its attention on Islamic values such as family, the role of women and the intersection of public and private spaces developed in a host society such as the Spanish one, specifically in Madrid and also Valencia.

The purpose of this paper is to explore the critical role of entrepreneurship among Arab women, not only as a way out of unemployment but also as a door to freedom, empowerment and independence. This has already been studied in other parts of the world where patriarchy still holds a grip (such as the Persian Gulf). Although the Spanish context is not at all free from gender bias, legislation and institutions defend the same opportunities for men and women, and we ask the following questions: How do public and private spaces intersect for Arab women entrepreneurs in Spain? Does the Spanish context affect the development of these women's professional careers? Do the entrepreneurial opportunities they encounter provide empowerment and agency in Spanish society? What are these women's motivations? Do they have to choose between a personal and a professional life? To what extent does entrepreneurship involve Arab women in the Spanish public space? In short, this paper intends to explore the main factors that affect, positively and negatively, Arab women entrepreneurs launching their ventures in Spain.

With this research, though it is limited, we would like to respond to the "growing need for survey-based attitudinal information capturing the self-expressed viewpoints, concerns, challenges and needs of women business owners" (CAWTAR report, 2007, 2) in this particular 
context and also counter some stereotypes that curtail Arab women's opportunities in the Western world.

This paper is organized in the following manner: we first contextualize the entrepreneurial background of some Arab countries that stand out because of their high level of total entrepreneurship activity (TEA). Then there is an analysis of the level of TEA in Spain along with a brief introduction to the phenomenon of immigration into the country in the past few years. We also explore the difficulties that curtail the agency of Arab women, such as patriarchy, interpretations of Islam and the complicated balance of work and family. The methodology is also explained along with the main results of our investigation. The conclusions gather the principal points from which future lines of research can depart.

\section{The Entrepreneurial Context}

The context, though it is not a determining factor, has a significant influence on entrepreneurial behavior. Thus, by examining the role of context in stimulating the extent and variety of such activity, we study the impact on outcomes in subsequent venture performance (Zahra and Wright, 2011).

In this section of the paper we analyze the context, considering three main aspects that subsequently affect the Arab women's entrepreneurial behavior. We first review the main factors that have helped Arab women to enter the labor market, such as the Arab Spring (2010) and the globalization process, given that "specific socioeconomic, political, market and institutional contexts are key to fostering, enabling and enacting entrepreneurial activity" (Al-Dajani and Marlow, 2013, 508). Economic necessity has also affected the percentage of necessity-driven entrepreneurship in Spain, as a mode of self-employment. Arab women in Spain, specifically in Madrid where most of our sample comes from, is studied in the next section, which also describes the Spanish entrepreneurial situation of the past year and the role immigrant women have played in it.

\section{Entrepreneurship in the Middle East and North Africa: An Overview}

According to the GEM 2014 Women's Report, countries in the Persian Gulf, invigorated by oil wealth and globalization, are encouraging Islamic financial institutions to offer funding opportunities and start-up capital. In a related vein, women in other countries in the Middle East and North Africa (MENA) are also finding a new way into the labor market through entrepreneurship. They too are affected by the globalization process - often due to economic necessity, a variable that inevitably affects women's entry into the global marketplace.

Globalization is usually cited in studies as the catalyst for reconciliation between cultures and as a powerful process that can "minimize the clash of civilizations" (Tlaiss, 2015, 874; see also Gray and Finley-Hervey, 2005, and Syed and Metcalfe, 2015). The entry of multinational corporations (MNCs) into MENA countries and their establishment there call for the reconsideration of some practices and for further knowledge and understanding of Eastern cultures, Islamic among them. Furthermore, globalization can be understood as a two-way road: on the one hand, MNCs "need to reconsider their knowledge of Middle Eastern culture and Islamic business ethics [...] when importing their practices from Western nations. Hence, 
performance evaluation standards, compensation principles, training and development, and promotion practices need to be reviewed in an attempt to tailor these practices to what is culturally sound and acceptable" (Tlaiss, 2015, 874-875). On the other hand, the widespread use of information and communications technology (ICT) is inevitably changing the gender dynamics in MENA countries. We have seen the predominant role of such technology in the Arab Spring, to cite one example. Thus, globalization is a growth medium for the empowerment of women and it also facilitates their involvement as a "vibrant and growing economic force" (Gray and Finley-Hervey, 2005, 203). However, there is a danger that Syed and Van Buren (2014) warn us against - the use of an "ethical imperialism" that defines gender dynamics from the Western perspective: "there is a danger that corporations will take it upon themselves to try to construct other societies-with values that those societies have chosen-in their own images without regard for the choices that societies, Islamic and otherwise, have made" (Syed and Van Buren, 2014, 270). Gender dynamics in Islamic countries are completely different from how they are understood in Western countries because, in MENA countries, "the role of women as mothers is paramount and Quranic notions of equality are based on gender differentiation rather than strict equivalence of roles within the home. An approach to understanding work-life balance built on an adaptation analysis would negatively cast the choices of women to balance work and family in ways that place the latter as primary evidence of patriarchy" (Syed and Van Buren, 2014, 269). We will develop this point later in the paper.

As for the point that entrepreneurship is linked to economic necessity, there is evidence of a preference for this form of self-employment. "In the MENA region, where female labor force participation rates are the lowest in the world, entrepreneurship can offer new opportunities for women to generate their own income, and help others as they do it" (CAWTAR report, 2007, 2). It has been demonstrated that "increasing levels of unemployment are likely to lead to higher levels of necessity entrepreneurship" (Noguera, 2013, 31). Specifically, "women are more likely to start a business out of necessity in a situation of economic recession than are men" (ibid.). In fact, "the difference in the entrepreneurial activity rates for men and women is smaller for "necessity" entrepreneurship compared to "opportunity" entrepreneurship" (ibid.). It goes without saying that entrepreneurship facilitates a work-family balance as it provides for a flexible arrangement of time and also space. In a related vein, as we mentioned before, new technologies (e-commerce) are opening novel ways for people to undertake innovative ventures from their homes, facilitating the needed conciliation. In the MENA region, the GEM 2014 Women's Report highlights the high TEA levels in countries such as Kuwait, Qatar and the United Arab Emirates, showing "high opportunity and capability perceptions and low fear of failure” (GEM 2014 Women's Report, 150).

In Figure 1, we list some of the characteristics of the female entrepreneurship wave in MENA countries. 


\section{Figure 1}

Main characteristics of female entrepreneurs in MENA countries

\begin{tabular}{|c|c|c|}
\hline $\begin{array}{l}\text { Female business in } \\
\text { MENA countries }\end{array}$ & Personal profile of the owners & Main challenges \\
\hline More than $\$ 100,000$ per annum & Average age: 35 to 54 & $\begin{array}{l}\text { Learning financial management } \\
\text { skills }\end{array}$ \\
\hline Sole owners of their firms & $\begin{array}{l}\text { Most of the women business owners } \\
\text { surveyed are married }\end{array}$ & $\begin{array}{l}\text { Finding and keeping good } \\
\text { employees (networking) }\end{array}$ \\
\hline Women are creating employment & $\begin{array}{l}\text { A good work-family balance is } \\
\text { identified as the greatest challenge }\end{array}$ & Access to capital and technolog! \\
\hline Extensive years of experience & $\begin{array}{l}\text { The women business owners see } \\
\text { their gender as a net positive rather } \\
\text { than an impediment to their business }\end{array}$ & The high cost of public services \\
\hline $\begin{array}{l}\text { Actively involved in managing their } \\
\text { enterprises }\end{array}$ & & Building skills \\
\hline Trading internationally & & Marketing opportunities \\
\hline Promoting ICT use & & Specialist training \\
\hline
\end{tabular}

Source: Prepared by the authors, based on a CAWTAR report (2007).

According to a recent study by the European Bank for Reconstruction and Development (EBRD, 2015) in other countries such as Egypt and Jordan, the entrepreneurial sector is underdeveloped, and women lack the information needed to start their own businesses as well as being denied access to financial resources, "which requires reforms at the legal and institutional levels to facilitate registration and women's access to information and loans." In a related vein, women in these countries tend to prefer the stability of regular employment that facilitates a work-life balance, as we will describe later in this paper. "The challenge is to change women's perspectives on entrepreneurship, making them realize that it can be an opportunity to transform their lives, rather than a financial necessity" (EBRD, 2015, 135).

In short, some MENA countries such as the ones in the Persian Gulf are embracing entrepreneurship, not only because of their financial stability deriving from oil wealth but also due to the gender bias in these countries, where entrepreneurship enables women to participate in the labor market while respecting the public and private dynamics, meaning that women do not enter the public space. In other countries such as Egypt and Jordan, a long road needs to be traveled to attain the same possibilities of financing and training for women.

\section{Entrepreneurial Context in Spain}

The entrepreneurial context in Spain has changed more and more in the past several years. According to the report GEM Spain 2014, after experiencing a decline in the previous year, the TEA rate in Spain grew to 5.47\%, which is a good rate despite the adverse environment. Nevertheless, this percentage is lower than the TEA rate of 7\% prior to the 2008 crisis. With 
regard to the motives that drive entrepreneurship in Spain, GEM Spain 2014 shows that $66 \%$ of the 2014 TEA rate corresponds to opportunity-driven entrepreneurs, while $29.4 \%$ corresponds to entrepreneurship driven by necessity due to the fact that Spain had been shaken in the previous years by a financial crisis that led to large-scale unemployment. This severe recession has influenced the rate of necessity-based entrepreneurship due to the inability of established companies and the formal economy to meet the demand for jobs. Table 1 compares the TEA rates in Spain and the average rate for the European Union, according to the main motives for entrepreneurship.

\section{Table 1}

TEA rates according to motivation in Spain and the European Union (\%)

\begin{tabular}{lccccc}
\hline Region & $\begin{array}{c}\text { Early- } \\
\text { Stage } \\
\text { Tea }\end{array}$ & $\begin{array}{c}\text { Necessity- } \\
\text { Driven }\end{array}$ & $\begin{array}{c}\text { Opportunity- } \\
\text { Driven }\end{array}$ & $\begin{array}{c}\text { Improvement } \\
\text { Driven } \\
\text { Opportunity }\end{array}$ & $\begin{array}{c}\text { Motivational } \\
\text { Index }\end{array}$ \\
\hline Spain & 5.5 & 29.8 & 66.1 & 33.5 & 1.1 \\
\hline Average for EU & 7.8 & 22.8 & 73.4 & 47.9 & 2.1 \\
\hline
\end{tabular}

Source: Prepared by the authors, based on GEM Spain 2014.

The gap between male and female entrepreneurs has diminished in the past two years and the average age for entrepreneurship in Spain is 35-44 years old. The typical profile of a business venture created in Spain is that of a small business providing services to local consumers and lacking in firm ambition to grow. Seven out of 10 new business ventures belong to self-employed people who do not employ any others. Compared to the European Union entrepreneurial rates, there is an imbalance between the TEA rate and the established business ownership rate in countries such as Spain and Greece "because those countries have a lower level of TEA compared to their level of established business ownership rates (Greece: 7.9 TEA vs.12.8 EB; Spain: 5.5 TEA vs. 7.3 EB). (...). This fact can be explained by the presence of a more efficient entrepreneurship ecosystem (education, R\&D transfer, access to finance, friendly regulatory framework) supporting new entrants in business activity. But so thin a basis of early-stage entrepreneurial activity can jeopardize economic canvas in crisis situation" (GEM 2014 Global Report, 12). In fact, data facilitated by the GEM project supports this statement (see Table 2). If we compare the percentages of new business creation with the percentages for established or discontinued businesses in the labor market, Spain has the lowest rate of nascent ventures but also the lowest percentage for discontinuation or closure of entrepreneurial ventures.

\section{Table 2}

Comparative of nascent and established business ventures (\%)

\begin{tabular}{lccccc}
\hline $\begin{array}{l}\text { Country/ } \\
\text { Region }\end{array}$ & Nascent & New Business & Tea & $\begin{array}{c}\text { Established } \\
\text { Business }\end{array}$ & Discontinuation \\
\hline Iran & 7.5 & 8.7 & 16.0 & 10.9 & 5.7 \\
Qatar & 11.3 & 5.4 & 16.4 & 3.5 & 4.8 \\
Asia (average) & 5.8 & 7.4 & 13.0 & 10.8 & 3.9 \\
Spain & 3.3 & 2.2 & 5.5 & 7.0 & 1.9 \\
EU (average) & 4.8 & 3.2 & 7.8 & 6.7 & 2.6 \\
\hline
\end{tabular}

Source: Prepared by the authors based on the GEM 2014 Global Report and GEM Spain 2014. 
Another important factor that underlines the GEM 2014 Global Report is that there is a high discrepancy between perceived abilities and perceived opportunities in countries affected by the crisis (perceived capabilities are 45.5\% vs. perceived opportunities 19.9\% in Greece; 48.1\% vs. $22.6 \%$ in Spain; and $46.6 \%$ vs. $22.9 \%$ in Portugal), which means that the financial crisis curtails entrepreneurial intentions (see Table 3).

\section{Table 3}

Perceived opportunities and perceived capabilities in Spain and the EU (\%)

\begin{tabular}{lcccc}
\hline $\begin{array}{l}\text { Country/ } \\
\text { Region }\end{array}$ & $\begin{array}{c}\text { Perceived } \\
\text { Opportunities }\end{array}$ & $\begin{array}{c}\text { Perceived } \\
\text { Capabilities }\end{array}$ & $\begin{array}{c}\text { Fear of } \\
\text { Failure }\end{array}$ & $\begin{array}{c}\text { Entrepreneurial } \\
\text { Intentions }\end{array}$ \\
\hline $\begin{array}{l}\text { Spain } \\
\begin{array}{l}\text { Average } \\
\text { (unweighted) for the EU }\end{array}\end{array}$ & 22.6 & 48.1 & 38.0 & 7.1 \\
\hline
\end{tabular}

Source: Prepared by the authors based on the GEM 2014 Global Report and GEM Spain 2014.

Due to the extremely high unemployment rate of young people in many economies (e.g., during 2013, Greece 57\%, Spain 54.9\%, Croatia 48.7\% and Italy 43\%), implementing entrepreneurship in these economies it is no longer "only an economic problem but a social and political one that demands the highest priority" so it can to be solved, according to the GEM 2014 Global Report (p. 44). Efforts should be directed to increasing the TEA level in Spain, working in the direction of increasing the perception of entrepreneurship as a good career choice $(53.9 \%$ in Spain vs. 56.9\% average (unweighted) for the European Union); giving a higher status to successful entrepreneurs (49.0\% in Spain vs. 66.6\% average (unweighted) for the European Union) and finally, providing more media attention to entrepreneurship (46.3\% in Spain vs. 53.3\% average (unweighted) for the European Union).

\section{Female Entrepreneurship in Spain and MENA Countries: A Comparative View}

The percentage of women intending to start a business is less than 10\% in Spain whereas in Middle Eastern countries such as Kuwait or Qatar it is around 50\%. A major reason studied by Noguera can be that entrepreneurship for women is intertwined with the " $5 \mathrm{M}$ framework" markets, money, management, motherhood and meso/macroenvironment - in the Spanish context. There are formal factors (access to financial resources and economic support programs, education level) and informal factors (perception of female entrepreneurs' skills, social networks, family context) that affect women's entrepreneurship in Spain. Furthermore, informal institutions are more important than formal institutions for the promotion of female entrepreneurship. (See also Álvarez et al., 2011.) According to this study by Álvarez et al., informal institutions or factors are constraints that affect the decision to become an entrepreneur or to look at entrepreneurship as a good option for work. In Spain, it is a fact that these informal factors (culture, social norms, social image of the entrepreneur) influence the level of entrepreneurial activity and have a larger influence on female than on male entrepreneurship (Álvarez et al., 2011).

In particular, the female TEA rate is less than 5\% of the adult female population in Spain. The rate is 7\% in Kuwait and more than 10\% in Qatar, according to data provided by the GEM 2014 
Women's Report. Even though the female TEA rate is lower for Spain, the rate of established business ownership in innovation-driven economies is higher for Spain (6\%) than for Qatar $(2 \%)$ and Kuwait (around 3\%). In economies where TEA rates are higher than the established business rates, women may face substantial challenges to sustain their businesses (access to capital and training). On the other hand, this could indicate that start-up activity has recently increased, whether through need or opportunity (which will show up in future years as increased established business activity). In sum, Spain has medium start-up rates, with a lower female TEA rate but higher stability and fewer risks than in MENA countries. This suggests a greater demand for entrepreneurship in developing economies, with comparatively fewer enterprises having made it to a mature stage, as mentioned before. Women in Spain have low opportunity perceptions, despite having high beliefs in their capabilities compared to the average for Europe (GEM 2014 Women's Report), matched by a greater fear of failure in Spain, compared to other countries such as Kuwait and Libya (GEM 2014 Report). Spain also lacks innovation and an international orientation generally, for both women and men. (See Table 4.)

\section{Table 4}

Comparison of male and female TEA rates: Spain, EU, Iran, Qatar, Asia and Oceania (\%)

\begin{tabular}{lcccccc}
\hline & $\begin{array}{c}\text { Male } \\
\text { Region }\end{array}$ & $\begin{array}{c}\text { Female } \\
\text { Tea }\end{array}$ & $\begin{array}{c}\text { Male } \\
\text { Tea } \\
\text { Opportunity }\end{array}$ & $\begin{array}{c}\text { Female } \\
\text { Tea } \\
\text { Opportunity }\end{array}$ & $\begin{array}{c}\text { Male } \\
\text { Tea } \\
\text { Necessity }\end{array}$ & $\begin{array}{c}\text { Female } \\
\text { Tea } \\
\text { Necessity }\end{array}$ \\
\hline Spain & 6.36 & 4.57 & 69.61 & 61.03 & 26.3 & 34.95 \\
Average for the EU & 10.21 & 5.45 & 75.29 & 69.91 & 21.32 & 25.47 \\
Iran & 21.45 & 10.47 & 59.38 & 63.04 & 39.77 & 36.43 \\
Qatar & 19.29 & 10.32 & 75.5 & 83.43 & 23.02 & 15.75 \\
Asia and Oceania (average) & 14.38 & 11.35 & 76.22 & 73.64 & 21.73 & 24.67 \\
\hline
\end{tabular}

Source: Prepared by the authors, based on the GEM 2014 Women's Report.

It is also noticeable that the entrepreneurial ventures that Arab women create do not identify with so-called survival entrepreneurship (EBRD, 2015; Morocco, for example), nor with the Persian Gulf type of entrepreneurship that comes from rich families endowed with training and professional expertise. These Arab women entrepreneurs are women from more or less disadvantaged backgrounds "who launch individual initiatives of income-generating activity and self-employment” (EBRD, 2015, 55).

\section{Arab Immigration in Spain}

Spain has one of the 10 highest per capita immigration rates in the world and the highest in the European Union. It also has the third highest immigration rate in the world in absolute terms, after the United States and the Russian Federation. The immigration flow has gradually fallen since 2012 due to the financial crisis.

With respect to background, something that is of interest for the research, there were 717,992 Moroccan immigrants in Spain in 2014. They made up the third most numerous group of immigrants from outside the EU and were the main Muslim group in Spain. Women constituted nearly half (49.5\%) of the group. In November 2015, according to data from Spain's Ministry of Employment, 201,766 Moroccan immigrants were affiliated to the social security system, forming the most numerous group from outside the EU. The main sectors for immigrant men 
and women in the general system are construction, hotels, commerce and vehicle repairs. In the self-employed sector, the main sectors are commerce, vehicle repairs, construction, hotels and especially the service sector.

According to the experts, immigration reproduces female and male roles and people's main aim in migrating is to overcome poverty and to guarantee the economic security of their families. Most immigrant women do low-skilled and poorly paid jobs (domestic workers mainly), reproducing the traditional female role (Cebrián, 2008).

This is why the importance of women is remarkable in the process of integration in the host country, as said above. Women are responsible for safeguarding their own cultures and families but they also have to enable their families to adjust to life in their host countries. It is important to understand the difficult balancing act of adjusting to what is new without discarding their roots. Host countries' policies and measures must ensure that, in this process, rights and duties are respected but also that immigrants are allowed full access to the information and services that will guarantee their complete integration in their host country (Cebrián, 2008).

According to Arjona (2006), the displacement of such women involved a huge mobilization of class and ethnic resources, meaning not only was there movement of finance capital but also of cultural and ethnic assets in strategies that go beyond the economic sphere. Arjona highlights the fact that these women are discriminated against, first because they are women and second because they are immigrants. Some of them arrive in their host country following a patrilocal pattern, whereby the woman abandons her place of origin to reunite with her husband. New processes (mainly derived from the economic environment in the host country) have resulted in immigrant women entering the workforce - with some difficulty - in niche markets, creating an ethnic economy. In this field, the two factors that most affect their incorporation into the professional market are the level of education (language skills) and the Islamic moral code that limits access to the public sphere and requires flexibility to balance work and family. Thus, entrepreneurship becomes a suitable alternative, as we will see later in this paper. Arjona (2006) describes this female immigrant group as a young and diverse one, with different backgrounds and educational profiles.

\section{Arab Women: Patriarchy, Religion and Family Commitments}

Having analyzed the context of entrepreneurship in some MENA countries and Spain, and immigration in the latter as external factors to bear in mind, we now explore the gender dynamics that are central to understanding the key role that religion and culture play in the establishment of male/female roles and therefore the way that religion, family and entrepreneurship intersect, something intrinsically linked to Arab women.

As already stated above, there are cultural biases - supported to a greater or lesser degree by the prescriptive teachings of religion, or rather interpretations of them - to women entering the public sphere. Traditional values and the "societal and familial dominance of males" (Gray and Finley-Hervey, 2005, 205) in Muslim societies affect and discriminate against women's careers as entrepreneurs (Jawad 1998; also Tlaiss, 2015). The dominance of patriarchal principles in cultural and traditional values specifically affect women's participation in the workforce in the Arab world and their chances of success in their entrepreneurial ventures (EBRD, 2015). 
As mentioned before, the role of women as mothers, caregivers and fundamental bases of the family is given priority over their engagement in the economic/public sphere. The education of girls in many Arab countries is a fact nowadays but the gap from there to the incorporation of women into the workforce remains to be filled in the years to come. (The World Bank calls this the "MENA paradox.")

We do not intend to make generalizations about a world as diverse as the Muslim world. Nevertheless, the sharing of a common set of beliefs and customs lets us introduce some patterns of behavior and ideologies. Previous entrepreneurship research argues that "there is an emerging trend for Muslim women to surpass the many rules and regulations in order to pursue their entrepreneurial intentions" (Gray and Finley-Hervey, 2005, 205), as data from the GEM project also reflected above. Studies show that entrepreneurship is becoming a new way of incorporating women to the labor market, even "supported and encouraged (Madichie and Gallant 2012), with the first wife of the prophet, Khadija, being a champion and prominent trader" (Tlaiss, 2015, 860). Nevertheless, it is recognized that Arab women entrepreneurs face problems specifically derived from this patriarchal view of culture and tradition, in the sense that men are the breadwinners, while women are the givers of life and have an invaluable task as mothers and guardians of the family. This fact affects and determines women's rate of employability in the Arab world and in other parts of the world as well.

It is important to highlight that within Islam there seems to be an emphasis on the diversity and complementarity of gender roles, rather than on the exact sameness of women and men in all spheres of life, unlike the common (Western) proposition of equality meaning sameness for men and women. Rather, "the Quranic notion of equality appears to be based on gender differentiation, not on identicality" (Syed and Van Buren, 2014, 259). Islam declares that a man is responsible for economically supporting his family members, including his wife and children, while placing a high value on a woman's role as mother (Syed and Van Buren, 2014). As a consequence, there is a set of expectations for both men and women in the family sphere, also imposed by their own families and society in general. Nevertheless, Syed and Van Buren (2014) note that this is a "nuanced perspective on gender roles within the Islamic world" (271), due to the fact that business necessity or economic necessity can blur these gender roles, as we will see later in this paper.

Furthermore, women's intersectionality between the private and public spheres is a problem still to be solved in these countries. "Traditionally, women's roles are relegated to the home, and to reproductive and unpaid care work (i.e. the 'private' sphere), whereas men's roles are associated with the marketplace, and productive and paid work (i.e. the 'public' sphere)" (EBRD, 2015, 27). This applies not only to the MENA countries but also to Western countries. (See also Buttner, 2001.) Here lies the main issue in which women and also men have to negotiate new rules, to surpass the "dominated/dominating relationship [...] particularly felt in the relationships between husband and wife" (Gray and Finley-Hervey, 2005, 204) in the private sphere but also in the public domain. The serious implications of crossing the boundaries of the public and private spheres have been explained as follows:

"Mernissi (1996) argues that the institution of paid employment in Muslim societies, Arab countries in particular, is a traditional domain of men, who consider it a matter of religious duty as well as male pride to support their wives. It is not unusual to find men who feel 'insulted if one asks them whether their wives work outside the home' (p. 64). A woman in paid employment is a traumatizing idea for such men, particularly those from lower literacy backgrounds. A narrow interpretation of Islamic female modesty has 
particularly served to remove women from the public space including paid employment. [...] Such patriarchal traditions seem to pose a major challenge to women's freedom and capability, including their freedom to pursue professional careers in Muslim societies" (Syed and Van Buren, 2014: 262). ${ }^{1}$

Thus, for men, the duty to bring food and money home is understood as a religious responsibility. This typical foundational premise of patriarchy is also attacked by the recently deceased Moroccan sociologist Fatima Mernissi in most of her work. She stated that “women's entry into public space [...] is thus felt as a castrating phenomenon by males whose identity is constructed on an idea of virility confounded with financial power and the control of female relatives' movements" (Rhouni, 2010, citing Mernissi (1987), Beyond the Veil: Male-Female Dynamics in Modern Muslim Society, Bloomington and Indianapolis: Indiana University Press).

Nonetheless, a specific negotiation is to be made in the Arab countries that follow sharia, where the positive law (labor and penal codes) and religious law (e.g., personal status codes, family laws and social norms) or, rather interpretations of them, conflict. This negotiation is the hard debate between a more modern approach to customs on the one hand, and the observance of the norms that safeguard tradition and cultural values on the other hand. This is defined as legal pluralism (EBRD, 2015; see also Gray and Finley-Hervey, 2005).

We posit that tradition and culture, specifically those that are entangled with religious values as observed in Islam, intersect in the Arab woman, whether in a Muslim country or abroad. The duty and social pressure to be a mother, to care for family and husband and to have children and raise them define the traditional role of women, sanctioned by sharia, by mullahs, by the law, by men, grandmothers and mothers - in short, by the whole of society. Furthermore, it can be also sanctioned by the high rates of divorces and separations in the Western world, where women have broken out of the private sphere and joined the labor market.

"[Mernissi] argues that historical Islam has deeply ingrained the fear of female sexuality in the male consciousness. Mernissi describes patriarchy in Islam as an organized system which treats gender equality as violation of Islam's (pre-supposed) premise that women must remain under the authority of a male relative (father or husband) and that they must be spatially or socially confined and excluded from matters other than those pertaining to family" (Syed and Van Buren, 2014, 264, citing Mernissi (1987), Beyond the Veil, 19).

We posit that Arab women (whether immigrants or not) live in the constant negotiation and revision of several concepts, whether they are conscious of this or not. Terms such as "patriarchy," "religion" and "family" define and complicate the lives of Arab women, positively and negatively. In fact, every woman feels and deals with the old statements of patriarchy and its remnants, the commandments of religion and family commitments. Nowadays, generally speaking, women do not have to choose anymore between family life and professional life. The promise of having it all leads women to a complicated juggling act with these different, separate spheres.

Nonetheless, we also posit that entrepreneurship (along with the other external factors cited above) is calling for a "silent revolution." The first reason for this is that Arab women

\footnotetext{
${ }^{1}$ Syed and Van Buren quote from F. Mernissi (1996), Women's Rebellion and Islamic Memory, London: Zed Publishers. See also a discussion of the importance of women's employment to attain a change in their status within the household in patriarchal societies such as Afghanistan and Pakistan in Faveri et al. (2015).
} 
entrepreneurs are reinterpreting the Qur'an. As Syed and Van Buren (2014) said, "the real challenge lies in how narrow and patriarchal interpretations and practices of religion could be reformed to bring about gender equality" (263). Second, women are fulfilling the dream of being breadwinners themselves. Back in 1982, Mernissi stated that "the basic, and the seemingly harmless, fantasy on the part of a woman of being a wage-earner in a Muslim society is definitely the first step in a silent but deep and overwhelming subterranean revolution" (Mernissi (1982), "Zhor's World: A Moroccan Domestic Worker Speaks Out," Feminist Issues 2(1), quoted in Rhouni, 2010). If women enter the economic scenario, then tradition is altered, patriarchy is shattered and family redefined, given that men are no longer the only family provider. This "subterranean revolution" alters also the spheres of politics and power. Commenting on article 155 of the 1957 Moudawana family code (prior to its 2004 revision), Mernissi explains "'the Moroccan husband is faced with anxiety-provoking ambiguities' since the law gives him the right to control his wife's movements, whereas economic reality confiscates it” (Rhouni, 2010, quoting Mernissi (1987), Beyond the Veil). A woman setting foot in public space changes everything and calls for a revision and updating of the world as we know it. For Mernissi, there is a "strong correlation between power relations underlying gender dynamics and the authoritarian form of power exercised at the level of politics in the context of neopatriarchy" (Rhouni, 2010, also in Gray and Finley-Hervey, 2005). As Mernissi herself stated, that step introduces chaos in both the public and private spheres because the frontier is altered. The frontier concept is a very interesting one in the work of Mernissi because the frontier stands for power or powerlessness. We do not say this happens only in the Arab world but these negotiations are more complicated in these countries due to the intermingling, as we stated before, of the political and religious powers that regulate both the private and public spheres, in a legal pluralistic society. According to Gray and FinleyHervey (2005), "it is central to recognize that Muslim social customs are based on the societal and familial dominance of males" (205), though, ironically enough, the factor of economic necessity and the blocked entry to business ventures (public space) result in entrepreneurship being a new way to enter the work/public sphere. We will come back to this point later in this paper.

Several studies have asserted that the Qur'an and some interpretations of it "exaggerate the sexual dimension of a woman while obliterating her economic identity" (Rhouni, 2010, 74, citing Fatna Ait Sabbah (1984), Woman in the Muslim Unconscious, New York: Pergamon Press). "This androcentric conception of femininity" nurtures women's unemployment and other economic circumstances, like the one stated above (virility equals financial power) and also the eroticization of gender relations. As Rhouni states, "women's access to work space [...] is often experienced as sexual aggression in a society in which women's bodies [... have] been controlled by the traditional division of space." In this sense, the European Bank for Reconstruction and Development states, "harassment in the workplace constitutes a large obstacle for working women," (EBRD, 2015, citing a newspaper article quoting Nilüfer Yllmaz from the Diyarbakır-based women's center KAMER). Yılmaz said, "no one is interested about the thoughts or education of women. What draws attention is a woman's body" (76). Also, the consideration of women as "legal minors" is a considerable obstacle in the professional life of women in MENA countries. The need for permission to move outside the private space restricts the possibilities of developing any kind of work or of obtaining permission to borrow money to launch a business. 
In short, the "dream of a regular paid job" (Rhouni, 2010) is not so easy to fulfill for women in the Arab countries. According to the EBRD 2015 report, in the MENA countries, these are the main factors that leave "little room for women to engage fully in the labour market" (29):

- Roles within households

- Care burden

- Household chores

- Sexual division of labor

First, their options are reduced to those jobs that do not require exposure in public. Islamic customs do not permit most forms of mingling of the sexes in public, so "women are usually not part of business transactions" (Gray and Finley-Hervey, 2005, 205). Second, the interplay of family life and professional life determines the options available to women.

"Women tend to prefer working in lower-paid positions in the public sector (i.e. civil service jobs) to the private sector because public sector jobs in the region tend to offer them more stability, more paid family leave and finance and credit options. The public sector also tends to have working hours that may facilitate better work and life balance” (EBRD, 2015, 8).

In other words, the family-related advantages of a job are a major condition for accepting that job, to procure a better balance of private and public lives. Third, "the [MENA] region is also characterized by the heaviest burden and the highest gender gap for unpaid work (household chores and care work) resulting in a large time deficit, which works to the detriment of incomegenerating activities" (EBRD 2015, 8). At this point it is also interesting to note that in the MENA region women devote up to five hours 24 minutes per day to household chores and care, compared to only 40 to 50 minutes attributed to men. There is an important difference from the average situation in OECD countries: women devote nearly the same amount of time (four hours 55 minutes) per day cooking, cleaning or caring but the main difference is that, on average, men in OECD countries spend two hours 35 minutes per day doing unpaid work. A study in Tunisia shows that "even the men who did not have a job would not take on a larger share of the household chores" (EBRD, 2015, 142). This is a determinant factor given that, if Muslim men do not help with household chores and care, women are overwhelmed and cannot work in a regular paid job. Generally, in both the OCDE countries and the MENA countries, a woman today has to learn how to juggle the different facets of her life, all of which are important and relevant to her, but we put forward the hypothesis that an Arab Muslim immigrant woman has more negotiations to do: religion, tradition, culture, a new host country, roots, work, family, etc. and all these spheres constitute a complex way of living in which she has to learn to tackle her possibilities. Furthermore, the understanding and support of the partner is what patriarchy still has a grip on. "The unequal burden of unpaid work is the result of the traditional status of women in a patriarchal social setting" (EBRD 2015, 143, referring to Turkey). We state that men in the MENA region are struggling with this new scenario while, in most OECD countries, some changes and stereotypes - though not vanquished at all - are being renegotiated already, as some conclusions from our exploratory study will demonstrate.

To sum up, all those frontiers that a woman must cross to attain independence and a certain economic status can be and already are being crossed through entrepreneurship. Some authors have stated that entrepreneurship is "a new frontier for Muslim women" (Gray and FinleyHervey, 2005, 205), being a real phenomenon in countries such Saudi Arabia and the United Arab Emirates, as well as Morocco and other countries in the MENA region, as shown above. 
Mernissi (1940-2015) argued all her life for a reinterpretation of the Qur'an that would lead to a new status for women in Islamic society. It is interesting to note that Arab women entrepreneurs are reinterpreting the Qur'an to come to a more individual interpretation of Islamic teachings and their practical applications to pursue their entrepreneurial ventures.

In fact, the main finding of Tlaiss's paper (2015) is that Islamic teachings derived from the Qur'an, as individually interpreted by Arab women entrepreneurs, "set the boundaries within Islam that accommodated their entrepreneurial activities" and by doing so "gained validation for their entrepreneurial careers, guidance on the ethical management of their businesses, and a shield from the traditional interpretations of Islam" (872). Tlaiss (2015) says there is "a need for a better understanding of how women's entrepreneurship does not conflict with socio-cultural or religious norms and how the environment can contribute to supporting this phenomenon" (874). In the end, Arab women are trying to demonstrate that they can juggle the public and private spheres, without minimizing or neglecting one for the other, while also reinterpreting the main prescriptions of Islam. We posit that the "silent revolution" has begun.

\section{Method}

The method of qualitative research employed in this study consists of a set of case studies, using the methodology design advanced by Yin (2003), based on a collection of personal accounts gathered from face-to-face interviews with individuals who meet predefined criteria, using interpretative phenomenological analysis (IPA) (Smith and Osborn, 2007).

The qualitative case study is an approach to research that facilitates the exploration of a phenomenon within its context using a variety of data sources, investigating a contemporary phenomenon within its real-life context, especially when the boundaries between phenomenon and context are not clear. This ensures that the issue is not explored through one lens but rather through a variety of lenses that allow for multiple facets of the phenomenon to be revealed and understood. This is the reason why we use this method because there are few studies that analyze the phenomenon we are studying with different lenses of inquiry.

Cope $(2011,608)$ praises the use of interpretative phenomenological research, saying "the strength of a qualitative research design such as this lies in its capacity to provide situated insights, rich details and thick descriptions. Richness is provided by paying close attention to both context and process." As our unit of analysis is the Arab woman entrepreneur, this methodology allows the researcher empirically to achieve a better understanding of the main factors that led an Arab woman to start a business in Spain, her relation with the context and how she overcome potential cultural barriers.

We developed seven case studies in order to explore differences within and between cases. The goal is to replicate findings across cases. We chose the cases carefully because we aimed to predict similar results across cases or to predict contrasting results based on a theory (Yin, 2003). In order to construct the case studies, we conducted interviews, which are particularly useful for getting the story behind a participant's experiences. The interviewer can pursue indepth information about the topic. Interviews may be useful as follow-up for certain respondents to questionnaires, to investigate their responses further (McNamara, 1999). We used a general interview guide approach. The guide approach is intended to ensure that the same general areas of information are collected from each interviewee. This provides greater focus than the conversational approach but still allows a degree of freedom and adaptability in 
getting information from the interviewee. We developed a semistructured interview guide on the basis of a literature review and input from community partners of the Arab women entrepreneurs.

Our study population was Arab women who had embarked on entrepreneurial projects in Madrid. However, as we were conducting a qualitative study, we did not aim to interview all of them but only enough of the women to provide a more in-depth comprehension of the different factors that influenced their decision to become entrepreneurs. We cannot claim to have fully exhausted every category of these factors but we consider we have identified the most relevant in relation to our conceptual framework.

We conducted seven interviews (one for each case) over a three-month period (September to November 2015). Semistructured in-depth interviews were conducted regularly with Arab women who were working as entrepreneurs in Spain or who had worked previously as entrepreneurs. These women had very different backgrounds, including different ages, origins and educational and social levels, and they worked at very different activities. They were identified with the help of Casa Árabe and through the researchers' personal contacts. Their names have been altered for reasons of confidentiality. The interviewees were first asked some demographic questions including personal questions about age, marital status, education and social background, the nature of their business, their previous employment and when they started their current business. The interviewees were then asked about their motivations and what drove them to open their own businesses, the impediments that they faced, their success stories, critical moments in business, and frustrations. Respondents were also asked to provide details about conflicts between their work and families and what they believed to be the best coping mechanisms. Many open-ended questions were asked, allowing the interviewees to elaborate on the issues raised (Itani, 2009).

The interviews aimed to probe four key issues:

1) What are the main barriers that Arab women entrepreneurs in Spain encounter when starting a business?

2) To what do Arab women entrepreneurs in Spain attribute their success?

3) What satisfies and what frustrates Arab women entrepreneurs in Spain as they try to start their ventures?

4) What recommendations can be made to alleviate Arab women entrepreneurs' situation and career opportunities? (Itani, 2009).

\section{Data Analysis}

We used a six-step thematic content analysis to identify themes representative of participants' perspectives. After a subsequent round of independent coding, the team met to compare initial themes and reached consensus themes. Interviews and iterative analyses continued until the saturation of major themes was achieved. We followed the pattern suggested by Marshall and Rossman (1989): organization of the data; generating categories, themes and patterns; and searching for alternative results. 
Participants gave their oral consent and completed a brief demographic characteristic survey. All the participants were interviewed at length (between 1.5 and three hours) in a semistructured interview with a trained female research assistant. The interview guide contained open-ended questions with predetermined probes designed to explore motivations and experiences regarding their specific problems.

The interviews were taped and later transcribed. The research questions examined the values and meanings of entrepreneurship and family or the lack thereof, motivations, education, roots, experiences, etc. The data collection took place in the context of Casa Árabe or in the interviewees' own houses or companies, in order to provide them with an appropriate environment for communicating their life experiences.

\section{Results and Findings}

This section examines the results from our study of Arab women entrepreneurs in Spain, set out according to how the interviewees responded concerning their motivations for becoming entrepreneurs and other factors that influenced their career development.

Our sample has been a diverse one, the women coming from four different countries (Morocco, Lebanon, Tunisia and Jordan) but having spent a large period of time living in Spain (from 10 to 33 years). They varied in age from 25 to 57 years old and had all been educated to secondary or tertiary level. They described themselves as Christians or Muslims, with a diverse level of religious commitment, and were between upper and lower-middle class. Four out of six were married with no more than three children. Our sample implies a broad spectrum of opinion and points of view but nonetheless the women shared common features that turned out to form a certain pattern. This was because similar factors motivated the women in their careers. These common features constitute the key alternative results of this paper.

Three categories emerged from the case studies: entrepreneurs' attitudes, Arab women and the context of Spain. (See Figure 2.) The factors that promote or restrict the entrepreneurship venture arise in the interrelation analysis of these categories, which we develop in the theoretical review.

Figure 2. Main categories

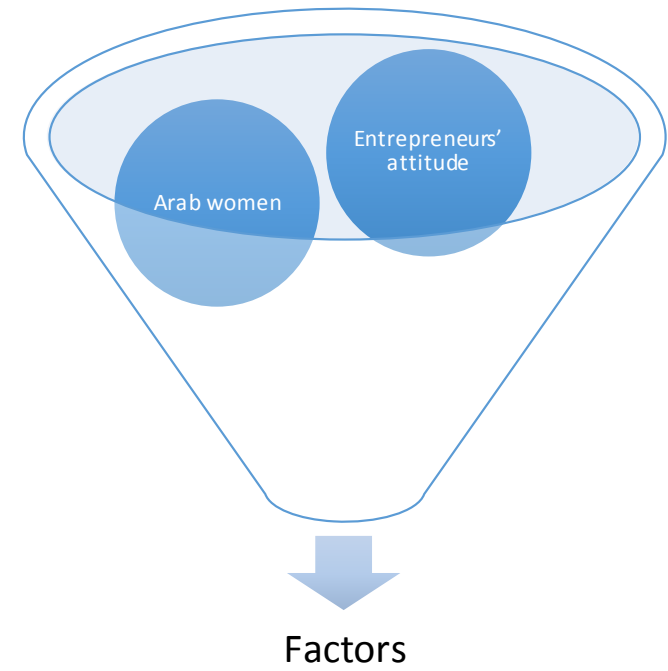

Source: Prepared by the authors.

16 - IESE Business School-University of Navarra 
Considering the pattern of Arab women in Spain, we posit that they are crossing the different frontiers that culture, stereotypes and the environmental context are putting in front of them. The intersectionality of public and private spaces in their lives calls for a renegotiation of gender bias, which they are conducting themselves, finding their own path in the world of entrepreneurship and economic independence in Spain.

We identified some common factors in the process of this study that characterized the Arab women entrepreneurs in Spain - namely, education, personal ambition, work-family balance, economic necessity and sociocultural patterns.

These factors are set out below. Following Noguera's classification (2013), we separate these factors between formal and informal factors. Formal factors include education and economic necessity; informal factors include personal ambition, work/family balance and social/cultural patterns.

\section{Formal Factors}

\section{Education}

It has been shown that general education, as measured in years of schooling, has a positive effect on entrepreneurial performance (Van der Sluis et al., 2006; Van der Sluis and Van Praag, 2007) and that business training is effective in improving the performance of people who applied for microfinance to start their own business (Karlan and Valdivia, 2006).

All the women in our sample have pursued studies in Western countries (the United States or Spain) and two-thirds of the women were encouraged by their own families to attain a good level of education, including language ability. One-third of the women were motivated by their own desire to pursue their dream of working, even though their families did not support them. The main reason why they migrated to Spain was education, including languages. Aisha has pursued her dream of creating her own clothes to tap into the niche market for Muslim clothing in Spain. She asserts that she always liked fashion and she learned how to sew from watching female members of her family do it. It was in Spain where she did a degree in pattern making and fashion, achieving high grades. She is now an entrepreneur with her own registered trademark, even though her family does not support her working. The case of Aisha fits the description Al-Dajani (2013) uses for displaced women who utilize "heritage entrepreneurship," in the sense that entrepreneurship is a form of earning money but also of "preserving and celebrating a cultural heritage" (505) through Aisha's designs (which she sews) for observant Muslim women.

Amina declares herself to be religious but not traditional - "we have adapted to Spain." She had an entrepreneurial venture running her own takeout restaurant. She maintains that her "modern" and open-minded views on business led to problems with some Muslim customers. One customer asked for Arab music to be played and Amina was threatened when she refused. She states:

“I've been raised in Spain and I know a man is no better than me and doesn't know more than me because he is older. If you trust in yourself, no one scares you." 
Imani was born in Spain, her father being Lebanese and her mother Spanish. She states that she always has to explain her roots:

"I have always been from here [Spain] but, when someone finds out my surname, they identify it as something different and start to judge me."

She also explains the cultural biases she encounters:

"I'm from Spain and from Lebanon, but here in Spain people assume I'm Lebanese and there [Lebanon] people assume I'm Spanish."

Imani says her family are modern.

"My father has not taught us Arabic. He wanted us to learn English. He is very openminded."

She also struggles with the veil:

"If you wear the veil here, people judge you only based on you wearing it. But to keep your mind at peace, you have to step outside [from Lebanon]. It helps you to be calm."

Alma is thankful for her language skills, which have opened doors for her outside. She also asserts that she has been raised in an open-minded family who are not very religious.

"I've been an entrepreneur since the moment I was born. I make things to last and there is continuous movement, like a river. I don't want still water."

She also asserts that the problems that an Arab women encounters have to do with education, not religion.

Hana has an extensive CV and is a university teacher, a former politician and an immigration expert in Spain. She says she is Spanish "though with Jordan in my heart." She formerly taught illiterate immigrant Arab women in Spain about their rights and the law.

"I used to teach them the law of their countries, though it is not ratified by the mullahs. [...] They didn't know anything about that. [...] There is a difference with the women who go to school and speak Arabic and French. They are at a higher level."

She also asserts she is open-minded and that her language skills opened doors for her. "It is the door to the outside world," she says.

Higher education, along with language skills, is positively associated with entrepreneurial ventures in our sample. Also, the positive encouragement of their parents to study abroad is a determinant factor for Arab women to take on new professional ideas.

\section{Economic Necessity}

As we stated before in this paper, economic necessity is a game changer, in the sense that it can open doors to a regular paid job for an Arab woman. Economic necessity can alter the private/public frontier. If she is to support the family, an Arab woman has to step outside her home, and the roles can be altered. Nevertheless, her work must be a respectable job, approved by sharia and Qur'anic norms of living. 
Alma stated in the interview that, when a family are in economic need, men do not tell women not to work.

"Roles in the Arab world are rigid. Women take money home and educate the children so, if there is enough money, women do not work outside the house. The right kind of job is one where there are no men, no alcohol, and it is not in a public area with men involved. A catering company is a good option, for example. It is also true that it is not the same if you have been living in Spain for 10 years or if you've just arrived. But the Qur'an states that the man is the provider and the woman has to take care of her husband but sometimes or in other countries it is just the opposite, depending on the economic necessity."

Alma also acknowledges women's role as providers for their parents back in Tunisia, if there is an illness or other problem.

Aisha comes from a lower middle-class family. In order to pursue her entrepreneurial venture, she works as a waitress to continue to develop her fashion project. She finances her business herself, which still makes little profit. She thinks it is a question of time to become known and to continue working hard.

Shirin has also been discriminated against by her American colleagues. They did not understand why Shirin was working outside home in her jewelry shop, given that she had a husband who provided for her and their two children.

“They didn't understand and that drove them crazy. Now I think what matters most is your personal project. By communicating and organizing, you move it forward. For me there were no difficulties in setting up my shop. I had some help. I wanted to do it for personal fulfillment and also to set an example for my kids.”

The fact that an Arab woman has spent some years in Spain, along with economic necessity in the family, can lead to acceptance of changed roles, altering the frontier of man/breadwinner and woman/caregiver. For a woman to succeed with this change, it must be accompanied by a more egalitarian distribution of household chores and care duties.

\section{Informal Factors}

\section{Personal Ambition}

Entrepreneurs are characterized as creative and imaginative people, who are socially competent to a high degree (Baron, 2000) and have a prevailing need for autonomy, freedom and independence in order to escape from "organizational constraints limiting their potential" (e.g., Chapman, 2000; Longenecker et al., 1988). Personal ambition plays an essential role in our sample, probably due to the fact that the women have to overcome significant obstacles to pursue their entrepreneurial ventures.

Aisha affirms that what is paramount is having a clear mindset about what you like and going for it, coupled with ambition and perseverance.

"I'm searching for personal fulfillment, something that fulfills me, that I like and that is mine. [...] I realised that, here in Spain, a lot of Muslim women don't dress properly 
because they don't find clothing that fits them. Then I thought that I know the customs, our own taste, our needs as Muslim women, so I thought I could do something about it, change something, contribute to offer a new image of the Muslim woman. That's where I started."

Aisha states, "I want to make something that fulfills me, and fashion does it. I have plenty of ideas, hopes and challenges."

She is young but ambitious:

"In Valencia and Spain I'm already known. Now I want to go abroad - for example, Morocco, Dubai, where my real target is, but also Paris... also the European woman. I want to be known in the whole world because I want my brand to create employment and wealth, tapping a real niche market. That is my professional ambition."

Furthermore, Aisha seeks to change what Muslim women wear in order to change the stereotypes with which they are perceived in Spanish society: "I want to change the stereotype of the Arab woman, always at home and dressed that way, with no personality."

Amina's case was different. After closing her takeout restaurant because of the Madrid train bombings of 2004, she dreams of becoming self-employed again. "If I could, I would be an entrepreneur," she says. "I have the ideas - I don't have the money."

Imani, an important filmmaker in Spain who is also known abroad, is interested in "how art can disseminate stories that have not been told or have been told wrongly told." She finds her Spanish and Lebanese cultural background puts her in an advantageous position.

"We have to tell something that, if it were not for us, wouldn't be told. It is that space that we are given as people telling a story as Spanish-Lebanese women. You tell an ordinary story, so that you empathize with the other. The stories we tell through our documentaries are human stories, not of violence but with a high emotional component."

Alma is a strong-minded Tunisian woman. "I knew I could not fail. I'm used to work on a goaldriven basis. I'm my own employer." Alma used to work for multinational corporations that hired her for her language skills. Now she is in charge of the language school at Casa Árabe in Madrid.

"I'm always alert, always with new projects and ideas. It's fertile ground. But in Spain people are really attached to their paycheck. I see that as stagnating. I'm happy because, since I've been in Spain, I've employed four teachers."

Alma is also a mother of triplets. In the interview, she explained how she managed her personal and professional life. "When I gave birth to my kids, I had to make do with my classes in Casa Árabe, and I only accepted evening jobs, from 6pm onwards, when my husband returned home from work. During the day I stayed with my babies." Alma works hard for two reasons: economic necessity and personal ambition.

"I want to improve every single day, for my family, for my future, for my family in Tunisia. I can't stop. I'm a nervous person. I work from Monday to Saturday. There are a lot of women like me. They are forgotten, though."

Alma does not deny the natural role of mothers. She believes babies have to be with their mother. "I have progressed in my life because I've had some help but also because I sleep five 
hours per day! It depends on the person and the resilience they have. You don't have to be scared but this has to do with the education." The following quote from Alma is worth highlighting:

"The Arab Muslim woman, in order to progress, has to sacrifice the family environment or her own personal life (marriage, etc.) or to stand up and not continue with all her professional achievements. I haven't sacrificed my personal life because I was very clear that I would marry whenever I could."

Shirin used to have a jewelry business in Madrid that was open for 12 years. She also shares some characteristics with the other women in the sample - that is, she is a strong character, open-minded, extrovert, confident and a hard worker.

Arab women in Spain share the dream of any woman - they want to attain something that is theirs in their own right, juggling family and work in perfect harmony.

\section{Family}

Family commitments are one of the factors that are harder to deal with - not only the obligations and responsibilities related to caring for parents and siblings but a woman's right to develop her own personal life, without being judged for taking the path of developing a professional project before a more personal project.

Muslim fashion designer Aisha had to fight hard for her dreams,

"Little by little, I have tried to be understood by my family. I've been a rebel in saying what I wanted. When my father told me to marry or work, I told him I wanted to study. He didn't agree. I had to leave the house. I was destroyed. My father didn't talk to me for six months. He didn't want to know anything about me. My mother cried a lot. But in my mind, everything was clear. It is not like I'm doing something wrong. I want to create my own life, what I want, to take my own decisions."

It is interesting to note how Aisha had to leave her father's house to pursue her dream, to leave the patriarchal sphere to live her professional life.

"Finally, my father had to understand. He is very religious. I'm religious too, Muslim to the bone, but here life changes. I can't live here as if I'm in Morocco. This is another world... It is impossible. Either you go mad or you stay at home without doing anything or you get married."

Aisha emphasized the transgression involved in a woman leaving her father's house when it was not to get married. "In Morocco, if you go out of your house it is to get married and if not...you are not respected anymore”. Now, she believes she is never getting married.

"As an observant Muslim woman, getting married now is nearly impossible. I used to have a boyfriend. He told me we could get married and I could continue working from home. In the fashion world, it is impossible."

The strong desire to go far in the fashion world, to have her own business, to grow and to build a big company in the future leads Aisha to think she has to sacrifice her personal life, meaning not getting married and not having children. However, Aisha's strong will to pursue her professional career is solid enough for her to give up family life. 
The case of family involvement in Amina's business venture was somewhat different. In fact, the idea of creating a takeout restaurant was about involving her mother in something professional, after a long illness. Amina nevertheless asserts that she would never start a business again with the family. "There was no accounting control. There were some disputes. I would launch a business again by myself."

Alma affirms that Arab women's lives have two facets: the professional one and the social and family one. It is also true that the household burden is very hard for women in general, Muslim or not, and whether they are married to a Muslim man or a Christian one.

"It is very complex for the Arab Muslim woman. If you ever go back to your country, even if you are 50 years old, you have to say you haven't had any boyfriend or sexual relations or have even drunk or smoked. There are double standards of morality, two faces. Women in the Muslim world go through two different phases: first you have to life by your father's rules, under his roof. Then you get married and it all depends on your husband. It depends whether he's open-minded or not. The same happens with Spanish men. A Spanish man also feels hurt if his wife is more successful than him."

Nevertheless, Alma acknowledges that she is not the boss in her own home. "I'm in charge of my children: their education, health, clothing, etc. But I'm not used to controlling my husband because my mother did not control my father or my brothers."

Hana's testimony also matches Alma's view of Spanish men:

"I've escaped from patriarchalism and I'm married to one of them... but he [Hana's Spanish husband] was happy that I wanted to do things. He was a pilot. I used to spend many hours alone. That's why I started a business, a language school."

Hana combined her work with raising her two children. "I devoted myself to them until they were eight years old, then I returned to university to study."

Shirin followed a different pattern. "When I was 40, we came back to Spain. My husband got a job in a bank and he did not have to travel so much, so I decided it was the moment for me to launch my jewelry business." It is important to note that Shirin gave priority to her personal/family project and before she then decided to be an entrepreneur and step into the public sphere.

"Nowadays, women are prioritizing their professional lives and later the personal. I've done otherwise and I have also succeeded."

However, she recognizes that she closed her jewelry business not only as a result of the 2008 financial crisis but also because of personal matters, but she is very satisfied with how she juggles both spheres.

"I have stepped out. I have been an entrepreneur. I now notice that my female friends and other female members of my family look at me to find out my opinion about things. But I also know that what matters is your personal project. Your family is what you do. It is your own project."

Alma also acknowledges the admiration that she provokes in her married sisters.

"They used to call me 'spinster' in Tunisia, saying that I was going to be a spinster all my life. But I have it clear in my mind: a woman without her own money, without her 
economic independence is no one, even more so if you have grown up in a poor family with no resources. I used to tell my sisters: don't get married - you have to work and study because, if you earn less than your husband, you can't fight. He would say to you: Why are you working? Your salary is nearly nothing - stay at home. Back in Tunisia, my father does not fight in front of me. I have earned that alone."

The involvement of family in the process of making plans for the future is a difficult one, as the women in our sample imply. Stepping outside the private sphere to develop a professional project sometimes implies being judged and misunderstood, even when a woman has reached the point of no return in the private sphere, meaning she cannot fulfill a personal project by having a family of her own.

\section{Social and Cultural Patterns}

Social and cultural patterns refer to the stereotypes these Arab women entrepreneurs have encountered in the process of creating their businesses, in Spain or in their own families, governed by other cultural traditions that curtail the professional motivations of the women in our sample. This stereotyped vision of the Arab woman is another barrier that they must surpass to carry out their projects.

Aisha, for example, stated in her interview:

"In Spain, other people see it as something weird - an Arab woman entrepreneur. Some of them are happy about it, and others are not really. In religion, I haven't encountered any prejudice but, when I was studying, some people told me to go back to my own country and things like that. I think they were just envious. I won a prize and they didn't like that."

According to Imani's view of the difference between men's and women's entrepreneurship, she stated, "in Spain I don't see differences between men and women or find that they discriminate against you for being a woman. Maybe in Morocco it's different but not here."

Filmmaker Imani asserted that "entrepreneurship has opened a lot of possibilities for us. Also, having the knowledge of that country [Lebanon] has allowed us to develop new projects."

Alma stated that "religion and family are two obstacles you must surpass to succeed in your professional career." However, she also indicated that not all veil-wearing women were oppressed by their husbands. Some of her teachers in the Casa Árabe language school wear the veil, they even have a $\mathrm{PhD}$ and "they are not oppressed by anything in the world. For them, it is a decision, their own decision."

On the other hand, Alma stated there are some Moroccan women who do not talk Spanish, so they formed their own community, with their friends in the mosque or in the market.

"These women have not stepped out of their countries of origin. There are lots of them. But their children they do step outside, go to university, etc. They do not stay at home, so generations are changing gradually."

Hana thinks otherwise:

"Immigrant people are more conservative because they feel lonely. They get together and begin to be stronger. In a way we are going backwards. I have also given classes to some 
illiterate Moroccan people. The husband of one of the participants asked me for a class only for women. I told him we were in Spain - the law does not allow that. After some years, people - most of them - have adapted to Spain and they like it here. But in the home sphere, there are a lot of different things, different dynamics for the Arab woman."

There is a need for immigrant women and their families to adapt gradually to the social customs and patterns in the host society. This adaptation goes hand in hand with education, which does not mean abandoning a set of personal beliefs but means mutual enrichment, of the host society and the immigrant woman.

\section{Conclusions}

This paper has explored the difficulties Arab women entrepreneurs in Spain face in their daily juggling of family and work, and how have they crossed the boundaries that surround them. One key implication of this study is that informal factors such as culture, social norms and family context particularly affect immigrant Arab women in the context of Spain. It is a fact that Arab women in Spain have to cross different frontiers, especially the family sphere. One of the reasons is that Arab women in Spain, having been in the country for a long time, have adopted the Spanish/Western way of life, in the sense of prioritizing a professional project over family life. Even though some of them proclaim themselves to be very religious, they accept a more moderate view of Islam, contributing thus to the "changing role of Muslim women" (Gray and Finley-Hervey, 2005, 215). Also education and language skills have been key to developing their professional ventures, regardless of their economic position. It is important to highlight the crucial role of family and how husbands have supported the personal ambitions of their wives (in a rather passive way), even though it is interesting also to note that two-thirds of our sample have left their entrepreneurial ventures, though they continue to be committed to a certain professional vein. The intersectionality of the public and private spheres through entrepreneurship creates some conflict, leading sometimes to a schism in professional and family life. In that case, the professional/public venture hinders entry into the private/personal life. In a very feminist way, we could say that some cases require the woman to have not only a room in the paternal home but a home of her own to pursue her professional and economic independence.

We posit that Arab women in Spain lack the necessary boost from the entrepreneurial ecosystem, which is so active now especially in Madrid. They do not receive financial aid or even training courses or information. In a positive way, it must be said that there are no legal restrictions on Arab women's entrepreneurship or gender bias that stops them from working and pursuing their dreams. The social norms dictated and preserved by their families are not strong enough in a liberal country to influence their decisions to attain professional careers. In this sense, it is also a Western pattern, for good or for bad, meaning the man is not the only breadwinner and the woman does not have only a reproductive role. Women, regardless of their origin, can enter in the Spanish public sphere, though it is up to them to leave that facet of their lives if their personal lives require it. So Arab women entrepreneurs share challenges with their Spanish counterparts but with the aggravating factor of sociocultural norms that perpetuate gender inequalities in the private sphere. Nevertheless, personal ambition and education enhance professional advancement and, if there are offspring, men in the OECD countries are expected to help more with childcare. Another important conclusion is that 
entrepreneurship can amplify women's impact on their community, something that is also supported in Al-Dajani and Marlow (2013).

To sum up, the "silent but deep revolution" is taking slow steps toward a greater degree of empowerment of Arab women in Spain. This affects their families, society and also the economic environment although, as Al-Dajani and Marlow (2013) state, entrepreneurship "is not a panacea to challenge patriarchy or a solution to inherent subordination" (518).

This paper contributes to women's entrepreneurship from a gender-aware framework based on the voices of the Arab women themselves. This study of Arab women entrepreneurs in Spain is a work in progress. Although we have conducted these interviews, we are conscious that more fieldwork is needed to achieve the saturation index and more rigorous conclusions. However, we posit that Arab women entrepreneurs in Spain, studied generally, are subject to more constraints and frontiers than their Spanish counterparts and also women entrepreneurs from other parts of the world.

Nonetheless, we believe the empowerment cycle through entrepreneurship has begun and it is slowly but firmly encouraging women to pursue their own economic independence, so that the "not-so-silent revolution" that Timmons (1994) referred to more than 20 years ago to define entrepreneurship in economic terms is now being transformed into that "overwhelming subterranean revolution" that Mernissi envisioned, when women will attain their economic independence, in an elegant exercise of juggling different spheres, changing the gender dynamics in Western and Eastern countries. 


\section{References}

Al-Dajani, Haya, and Marlow, Susan (2013). "Empowerment and Entrepreneurship: A Theoretical Framework." International Journal of Entrepreneurial Behaviour and Research 19(5): 503-524.

Álvarez, Claudia, Urbano, David et al. (2011). "Environmental Conditions and Entrepreneurial Activity: A Regional Comparison in Spain." Journal of Small Business and Enterprise Development 18(1): 120-140.

Arjona, Ángeles (2006). "Mujer inmigrada y emprendedora." In Arriaga, Mercedes, and Baca, Jesús (eds.) Desde Andalucía: mujeres del Mediterráneo.

Baron, R. (2000). "Psychological Perspectives on Entrepreneurship: Cognitive and Social Factors in Entrepreneurs' Success." Current Directions in Psychological Science 9: 15-19.

Buttner, E. Holly (2001). “Examining Female Entrepreneurs' Management Style: An Application of a Relational Frame." Journal of Business Ethics 29: 253-269.

Cebrián, I., and Moreno, G. (2008). Cómo abordar la integración de las mujeres inmigrantes. Guia para las Administraciones Públicas. Madrid: University of Alcalá and the Institute of Women (Instituto de la Mujer).

Center of Arab Women for Training and Research (CAWTAR) (2007). Women Entrepreneurs in the Middle East and North Africa: Characteristics, Contributions and Challenges. Tunis.

Chapman, M. (2000). “When the Entrepreneur Sneezes, the Organization Catches a Cold': A Practitioner's Perspective on the State of the Art in Research on the Entrepreneurial Personality and the Entrepreneurial Process." European Journal of Work and Organizational Psychology 9(1): $97-101$.

Cope, J. (2011). "Entrepreneurial Learning From Failure: An Interpretative Phenomenological Analysis." Journal of Business Venturing 26(6): 604-623.

European Bank for Reconstruction and Development (EBRD) (2015). Enhancing Women's Voice, Agency and Participation in the Economy. London.

Faveri, Christine, Wilson, Kerry Jane, and Shaikh, Perveen (2015). "Making Markets Work for Women: How Push and Pull Strategies Can Support Women's Economic Empowerment." Enterprise Development and Microfinance 26(1): 11-22.

Global Entrepreneurship Monitor (2014). GEM 2014 Executive Report: GEM Spain. http://gemconsortium.org/docs.

Global Entrepreneurship Monitor (2014). GEM 2014 Global Report. Available at www.gemconsortium.org/report.

Global Entrepreneurship Monitor (2014). GEM 2014 Special Report: Women's Entrepreneurship. Available at www.gem-spain.com/wp-content/uploads/2015/03/GEM-2014womens-report.pdf. 
Gray, Kenneth R., and Finley-Hervey, Joycelyn (2005). "Women and Entrepreneurship in Morocco: Debunking Stereotypes and Discerning Strategies." International Entrepreneurship and Management Journal 1: 203-215.

Karlan, D., and Valdivia, M. (2006). "Teaching Entrepreneurship: Impact of Business Training on Microfinance Clients and Institutions." Working paper.

Longenecker, J.G., McKinney, J.A., and Moore, C.W. (1988). "Egoism and Independence: Entrepreneurial Ethics." Organizational Dynamics 16(3), 64-72.

Marshall, Catherine, and Rossman, Gretchen B. (1989). Designing Qualitative Research. Thousand Oaks, California: Sage.

McNamara, Carter (1999). General Guidelines for Conducting Interviews. Minnesota.

Noguera, María (2012). "Female Entrepreneurship in Catalonia: An Institutional Approach." Doctoral thesis. Barcelona: Universitat Autònoma de Barcelona (Autonomous University of Barcelona).

Rhouni, Raja (2010). Secular and Islamic Feminist Critiques in the Work of Fatima Mernissi. Leiden: Brill.

Smith, J.A., and Osborn, M. (2008). "Interpretative Phenomenological Analysis." In Smith, J.A. (ed.), Qualitative Psychology: A Practical Guide to Research Methods, second edition. London: Sage, pp. 51-80.

Syed, Jawad, and Van Buren III, Harry J. (2014). “Global Business Norms and Islamic Views of Women's Employment.” Business Ethics Quarterly 24(2): 251-276.

Timmons, J.A. (1994). New Venture Creation: Entrepreneurship for the 21st Century. Irwin Press.

Tlaiss, Hayfaa A. (2015). "How Islamic Business Ethics Impact Women Entrepreneurs: Insights From Four Arab Middle Eastern Countries.” Journal of Business Ethics 129: 859-877.

Van der Sluis, J., Van Praag, M., and Van Witteloostuijn, A. (2006). "Why Are the Returns to Education Higher for Entrepreneurs Than for Employees?" Amsterdam: University of Amsterdam. Working paper.

Van der Sluis, J., and Van Praag, C.M. (2007). "Returns to Education for Entrepreneurs and Employees: Identification by Means of Changes in Compulsory Schooling Laws." Amsterdam: University of Amsterdam. Working paper.

Yin, R.K. (2003). Case Study Research: Design and Methods, second edition. Thousand Oaks, California: Sage.

Zahra, S., and Wright, M. (2011). “Entrepreneurship's Next Act.” Academy of Management Perspectives 25: 67-83. 